Tvaronavičienė, M., Shishkin, A., Lukáč, P., Illiashenko, N., \& Zapototskyi, S.

(2017). Sustainable economic growth and development of educational systems.

Journal of International Studies, 10(3), 285-292. doi:10.14254/2071-8330.2017/10-

$3 / 21$

\title{
Sustainable economic growth and development of educational systems
}

\section{Manuela Tvaronavičienè}

Department of Business Technologies and Entrepreneurship

Vilnius Gediminas Technical University, Vilnius, Lithuania

Email:manuela.tvaronaviciene@vgtu.lt

\section{Anatoly Shishkin}

Plekhanov Russian University of Economics

Moscow, Russian Federation

Email:shishkin.av@rea.ru

\section{Peter Lukáč}

Faculty of Social Sciences,

University of Ss. Cyril and Methodius in Trnava

Trmava, Slovakia

Email:plukac@me.sk

\section{Nataliia Illiashenko}

Department of Marketing and Management of Innovation Activity,

Sumy State University

Sumy, Ukraine

Email:nat.illiashenko@gmail.com

\section{Sergii Zapototskyi}

Taras Shevchenko National University of Kyiv

Kyiv, Ukraine

Email:zapototsk@ukr.net

Abstract. This paper is focused on the issue how educational systems might increase the economic and business potential of the regional centers and contribute to the innovations and sustainable economic development. Rapidly growing economies are marked by social fragmentation and economic divisions but have the potential to become the drivers for shrinking social divisions and creating opportunities for all the citizens. Carefully designed educational policies becomes a solution for most of the economic and social problems by offering formal and non-formal educational activities. Policy-makers in the educational realm learn to engage with the realities of social exclusion, political alienation, and economic marginalization - through both public policy and private initiatives. Educational initiatives and policies across might include carefully orchestrated public policies, spending the money from the structural funds all aimed at stabilizing communities and establishing cooperation and integration, non-formal educational initiatives to
Received: April, 2017 1st Revision: August, 2017 Accepted: October, 2017

10.14254 $8330.2017 / 10-3 / 21$ 
reduce marginalization, or expansion of the formal school system aimed at raising aspirations.

Keywords: education, educational systems, innovations, structural funds, economic growth.

JEL Classification: H4, I12, I24, R51.

\section{INTRODUCTION}

Educational policies represent one of the most important solutions for solving the inequality in the regional development, social fragmentation and unrest, as well as to contribute to the economic growth using both pathways of structural support from the governments (e.g. EU funds or regional development funds) and innovational strategies that boost up innovations in economic and social life. Within these policies a special importance is attributed to the process of the lifelong learning that represents learning which is pursued throughout the course of one's lifetime or the learning which is diverse, flexible and accessible at different places and times. Lifelong learning crosses sectors, enhancing learning beyond traditional education and all through adult life. The definition is founded on four pillars of learning for the future as described by International Commission on Education for the Twenty-First Century and Delors (1996): learning to know - the need to master learning tools instead of acquiring structured knowledge; learning to do - preparing individuals for the forms of work required currently and in the future such as innovation and adapting learning to future work settings; learning to stay together and with other people peaceful resolution of conflict, discovery of other persons and their cultures, boosting community capability, personal capacity and competence, social inclusion and economic resilience; and learning to be - learning contributing to an individual's whole growth: spirituality, aesthetic appreciation, sensitivity, intelligence, body and mind.

Educational policies and lifelong learning are very crucial concepts both for the young and old: in fact, both categories might be influenced by it and both can profit from acquiring new skills and knowledge that might prove to be crucial for securing and maintaining their position on the turbulent labor market as well as at other markets (Voogt et al., 2013; Janda et al., 2013; Koudelková and Svobodová, 2014; Balitskiy et al., 2014; Strielkowski and Ćábelková, 2015; Oganisjana et al., 2017; Sokół and Figurska, 2017; Ignatjeva et al., 2017; Gulicheva and Osipova, 2017; Nguyen et al., 2017; Michailova et al., 2017). New technologies that are starting to emerge and dominate the world markets require constantly adapting and enhancing one's skills and qualifications (Čajka et al., 2014; Strielkowski, 2017; Akhter, 2017, Zemlickiene et al., 2017).

Lifelong learning might impart responsiveness, initiative, and creativity in people, thus facilitating them to demonstrate adaptability in post-industrial society by fostering skills for managing uncertainty, communicating within and across cultures, sub-cultures, communities and families, and negotiating conflicts (De Beer et al., 2015). A report by Aspin and Chapman (2001) stated that lifelong learning provides a holistic outlook on the purpose of education in an individual's life cycle. It upholds that education, as a continuous life process, plays an important role in allowing people to adapt to, and address new challenges and shifts in their lives and the environments they live. Lifelong learning, taking on all kinds of educational as well as learning experiences, aids people in engaging in meaningful interactions with their society through developing their skills, knowledge and critical thinking capabilities. Implicit in the lifelong learning idea is the life wide learning concept. Despite the fact lifelong learning puts emphasis on the continuity of learning 
all through the human life cycle, life wide learning recognizes that individuals find it essential to engage in several learning activities at the same time, through different modalities and in diverse settings.

The goal of lifelong learning is to allow people to turn out to be active social agents - persons who have the capability of acting, reflecting, and responding properly to the developmental, social and cultural changes which they encounter bother as individuals and as societal members (Aspin and Chapman, 2001). Life wide learning, therefore, relates to the parallel and multiple roles of an individual in the society, as an additional aspect of lifelong learning. Overall, in today's world in human life cycle, the traditional focus on creating the basis of basic knowledge as well as competencies and acquirement of the technical and intellectual tools of learning in the first life quarter has to be accompanied by lifelong learning in a learning society in which all take part in and contribute to education all throughout life.

Educational policies are of a special importance for the backyard regions or neglected or economically impaired territories (Safrankova \& Sikýr, 2016). These territories often suffer from high unemployment, structural problems, social issues such as criminality, low level of education, social unrest and tensions. The right way of selecting and implementing these policies might change a lot and ameliorate the future of these regions.

\section{LITERATURE REVIEW}

The conceptualization of educational policies and lifelong learning often relies on the approach that includes the promotion of skills and competencies required for the development of general capabilities as well as specific performance in work settings. Competencies and skills developed through policies and programs of lifelong learning would be very important for workers performance in their dealing with precise job responsibilities and the ways they could adapt their particular and general competencies and knowledge to new jobs. Therefore, a more vastly skilled and workforce in slums or third world cities would contribute to a more competitive and advanced economy in Third World countries (Auerbach, 2015). There is also a spillover effect in the form of migration of the young and skilled agents to the markets in the more developed markets where their skills might be in higher demand (Fraser, 2011).

The same, of course, applies to the developed countries of the developed Western economies. As the population is aging, more and more stress is put on the "gig economy" where users have to be highly-skilled and intellectual agents that can easily adapt the working environment and to reveal their preferences for goods and services (Jenkins et al., 2003).

The United Nations Educational, Scientific and Cultural Organization (UNESCO) defines the lifelong learning along the following lines: "Lifelong learning is less about the teaching or training of certain things or specific skills, much more a way of describing a process of empowerment and mechanisms through which local communities are exposed to varied learning opportunities that helps to prepare them for anticipating the unknown and tackling the political and social uncertainties of tomorrow. In a word, it is that that prepares them for sustainable futures" (UNESCO, 2015).

Citizens may have their outlook of the world and ability for rational choice constantly expanded and changed through the educational experiences as well as cognitive achievements provided by lifelong learning. Besides, along with the provision of lifelong opportunities offered through traditional agencies and institutions, there is a trend for providing opportunities for lifelong learning by creating and expanding various community initiatives (Biesta, 2006). Such form of the community as an institution and platform for lifelong learning thrives in the realization that the people who engage in lifelong learning would enjoy an array of alternatives, from which they could construct an enriching and satisfying life-enhancing activities pattern. 
Moreover, according to UNESCO (2015), "a learning city provides lifelong learning for all" and that 'lifelong learning lays the foundation for sustainable social, economic and environmental development' on all of the four levels (international, regional, local and citizen)".

Educational policies and lifelong learning would offer slum dwellers the opportunity of updating their knowledge of tasks which they had formerly laid aside or all through wished to attempt but were unable; to attempt pursuits and activities which they were previously made-believe were beyond their competence or time; or to work towards the extension of their intellectual horizons through pursuing to understand and become proficient at some of the present cognitive advances, which have transformed other parts of the world (Lee and Morris, 2016). Nevertheless, lifelong learning is not constrained to those above the education age in institutional or informal settings. Expanding cognitive repertoire and the growth of competencies and skills may continue all the way through life, as a critical part of persons' growth and development as humans and as residents in a participative social equality, as well as being productive representatives in economic development. Community and individual wellbeing is promoted and protected through making such activities, and the resources for supporting them, accessible to the broadest range of populations. Lifelong learning is a public good - it benefits the society as a whole, and individuals also.

According to Aspin and Chapman (2001), the accessibility of learning opportunities over the entire lifespan of people is a pre-requisite for effective and informed involvement in a democratic society. People might only develop as autonomous agents with the ability of entirely taking part in society when they are adequately informed, pre-disposed and prepared; if they are well-fed and healthy; when they have the minimum domestic conditions for the perpetuation of existence; and when they could involve themselves in communication with their correspondents, enjoying similar autonomy as they have themselves, and with the people they can converse with, consider and plan for mutually beneficial means of action.

\section{METHODOLOGY}

Education and learning being a public good as well as a responsibility shared by all for the mutual benefit of all societal members are central to this form of the requirement for lifelong learning for all. Structural funds are particularly powerful in contributing to these policies. In addition, participation in lifelong education is an essential prerequisite to an ongoing part of engagement in the organizations of democracy (Ahmed, 2014). Safeguarding the future of all citizens in slums and third world cities is secured through assuring them access to every field and form of human knowledge, understanding and collaborating in a high-quality, dynamic and comprehensive curriculum in multiple institutions committed to the learning and education of the present and future generations. Such a program offers individuals with one of the key ways of personal empowerment, clear understanding and informed decisions in performing day-to-day activities and participating in the growth of the economy of the slums or third world cities and the country as a whole.

According to Ahmed (2014), lifelong learning is critical as it helps in developing the autonomy along with a sense of responsibility of communities and people, in reinforcing the ability to tackle the transformations occurring in the society, culture and economy, and in promoting tolerance, coexistence and the creative and informed engagement of people in their communities. If communities, corporations and governments accept lifelong learning principle it indicates that people could expect support in their attempts of acquiring and updating the latest skills and knowledge which is vital to their daily work lives, wherever and whenever they require them. Such enables the personal development of the residents, and improves their employability, social capacity and mobility to be effective in involving themselves in activities aimed at improving the quality of life in the cities (Power and Maclean, 2011). 
This paper uses an analysis of the data from Eurostat (2017) on participation rate in education and training in the age group from 18 to 64 years across the EU Member States. We analyze the adult learning patterns for males and females, as well as for all groups together. Moreover, we compare the patterns that is visible across various groups of EU Member States and two other countries that can be found in the EU proximity and have great importance for the economic and social growth of the EU, namely the Former Yugoslav Republic of Macedonia (FYROM) and Turkey.

Our methodology involves the cross-country comparison using the available data as well as graphical data visualization that portrays most common trends and shows the patterns.

\section{MAIN FINDINGS}

The results provided in Table 1 show that the European Union (EU) set up an ambitious goal for itself that envisages an average of at least $15 \%$ of adults aged 25 to 64 years old should participate in lifelong learning by 2020 . Currently, the participation rate is at $10.8 \%$.

Table 1

Education and training in the age group from 18 to 64 in the EU Member States, FYROM and Turkey (2007 and 2016), males and females (in \%)

\begin{tabular}{|c|c|c|c|c|}
\hline \multirow[t]{2}{*}{ States } & \multicolumn{2}{|c|}{2007} & \multicolumn{2}{|c|}{2017} \\
\hline & Males & Females & Males & Females \\
\hline EU 28 & 14.3 & 16.4 & 15.6 & 17.6 \\
\hline EU 27 & 14.4 & 16.5 & 15.7 & 17.6 \\
\hline EU 15 & 15 & 17.4 & 17.2 & 19.3 \\
\hline FYROM & 9.2 & 10.2 & 8.7 & 10.2 \\
\hline Turkey & 6.8 & 4.7 & 12.2 & 10.8 \\
\hline
\end{tabular}

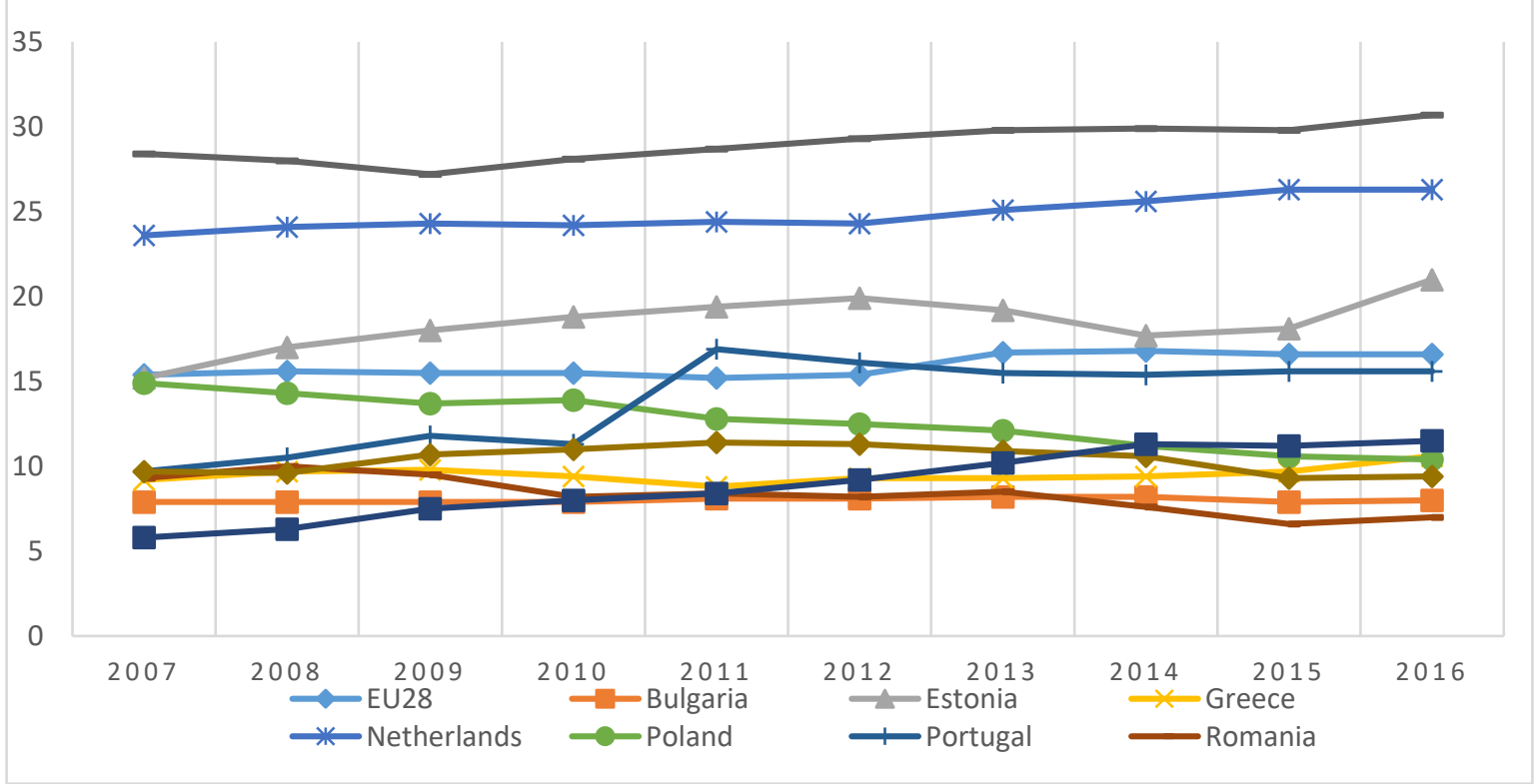

Chart 1. Dynamics of adult learning in the EU and neighboring countries (2007-2017), in \% Source: Own results 
It becomes apparent from Table 1 that the participation in lifelong learning in the EU countries is greater than in its immediate neighbours, FYROM and Turkey. However, one can see that over the past 10 years, Turkey has achieved a growth from $6.8 \%$ to $8.7 \%$ for males and from $4.7 \%$ to $10.8 \%$ for females which is similar in its dynamics to the EU countries, while FYROM recorded a slowing rate for males and did not report any increase for females.

Furthermore, Chart 1 above shows the graphical analysis of the data using the chart form for the EU and neighbouring countries regardless of the gender. It becomes clear that the adult learning in some EU countries is greater than in the other. Moreover, one can see that Netherlands, France, Luxembourg and Estonia were the only other Member States where the participation rate in 2016 already exceeded the $15 \%$ benchmark. By contrast, Romania, Bulgaria, Slovakia, Croatia, Poland and Greece reported adult learning rates of $4.0 \%$ or less (Eurostat, 2017).

Overall, it appears that lifelong learning differs in countries with regard to such factors as economic growth, rate of learning, labour market characteristics, social and economic specifics and a plethora of other factors. However, one thing is clear: lifelong learning represents an enormous potential that has to be exploited by the relevant stakeholders and policy-makers. It becomes clear that more dynamic countries or countries aspiring at fostering their economic growth and well-being are keener on investing into lifelong learning and related issues thus promoting sustainable economic growth and development, including, far and foremost, urban development in both slums of the Third World and modern-day smart cities.

\section{CONCLUSIONS}

As the global challenges arise in the world for the world economies to face them, educational policies and lifelong learning has developed to be among the main ways of enhancing the quality of life during the $21^{\text {st }}$ century. Today, it is insufficient to have an all-encompassing initial education - one should continue acquiring new skills and knowledge for taking advantage of the new opportunities which advance technological and scientific advancements bring, and to adapt to the hardships of life in the changing world. Evidently, investing in lifelong learning would be a payoff to both third world nations and their citizens, in terms of productivity, employment, health, income and other benefits.

Furthermore, provision of opportunities to learn all through life would become a critical factor in the fight against eradicating poverty and the education of people for sustainable development. Yet, the adoption of the lifelong learning principle would require a new vision, one which will shift the focus from education to learning; one which would move to a more user-friendly and seamless system; one which would recognize the different ways through which skills and knowledge may be acquired in the digital age beyond the formal system. As pointed out by Power and Maclean (2011), particularly, for a progress to be made in the reduction of poverty and guaranteeing of sustainable development in the developing world, the international community and governments will be required to fulfill their responsibilities and take the necessary measures in making lifelong learning for everybody a reality.

Educational policies and lifelong learning might become a facet of economic growth, most notably sustainable economic growth in both developed and developing economies. It can alter the composition and the structure of labour force which, in turn, might lead to shifting the axis of labour and capital ratio for the local economies. Moreover, it might promote business development through the creation and cultivation of the new business leaders who might invest into further development of the countries in question and their economies.

Interested stakeholders and policy-makers should think about the exploitation of the potentials of the educational policies and lifelong learning. Careful and planned implementation and widespread use of 
lifelong learning, if applied systematically, might lead to unprecedented changes in the economy. With regard to the above, one cannot underestimate the potential of the structural funds that might foster the educational policies and lifelong learning and help to ameliorate the level of education and the level of life in many countries.

\section{REFERENCES}

Ahmed, M. (2014). Lifelong learning in a learning society: Are community learning centres the vehicle. Education, learning, training: Critical issues for development, 102-125.

Akhter, F. (2017). Unlocking digital entrepreneurship through technical business process. Entrepreneurship and Sustainability Issues, 5(1), 36-42. doi: https://doi.org/10.9770/jesi.2017.5.1(3).

Aspin, D., \& Chapman, J. (2001, July). Lifelong learning: concepts, theories and values. In Proceedings of the 31st Annual Conference of SCUTRE $A$ (pp. 38-41). University of East London: SCUTREA.

Auerbach, A. M. (2015). India's urban constituencies revisited. Contemporary South Asia, 23(2), 136-150.

Balitskiy, S., Bilan, Y., \& Strielkowski, W. (2014). Energy security and economic growth in the European Union, Journal of Security \& Sustainability Issues, 4(2), 123-130. http://dx.doi.org/10.9770/jssi.2014.4.2(2).

Biesta, G. (2006). What's the point of lifelong learning if lifelong learning has no point? On the democratic deficit of policies for lifelong learning. European Educational Research Joumal, 5(3-4), 169-180.

Čajka, P., Jaroszewicz, M., \& Strielkowski, W. (2014). Migration Incentives and Flows between Belarus, Moldova, Ukraine and the European Union: a Forecasting Model. Economics and Sociology, 7(4), 11-25. http://dx.doi.org/10.14254/2071-789X.2014/7-4/1.

De Beer, A., S., Láb, F., Strielkowski, W., \& Tejkalová, A. (2015). Business influence on media news processing: a comparison of journalists' perceptions in the Czech Republic and South Africa. Economics and Sociology, 8(1), 222-233. http://dx.doi.org/10.14254/2071- 789X.2015/8-1/17.

Eurostat. (2017). Adult learning statistics. Retirieved from http://ec.europa.eu/eurostat/statisticsexplained/index.php/Adult_learning_statistics.

Fraser, B. (2011). Growing up in Rio's favelas. The Lancet, 377(9779), 1735-1736.

Gulicheva, E., \& Osipova, M. (2017). Program-target method of pricing for international educational services. Czech Journal of Social Sciences, Business and Economics, 6(1), 21-27. doi: http://dx.doi.org/10.24984/cjssbe.2017.6.1.3.

Ignatjeva, S., Volosnikova, L., \& Efimova, G. (2017). Assessment of inclusive educational space in higher education institution. Journal of Security and Sustainability Issues, 7(1), 123-132. doi: https://doi.org/10.9770/jssi.2017.7.1(10).

International Commission on Education for the Twenty-First Century, \& Delors, J. (1996). Learning, the Treasure Witbin: Report to UNESCO of the International Commission on Education for the Twenty-first Century: Higblights. Unesco Publications.

Janda, K., Rausser, G., \& Strielkowski, W. (2013). Determinants of Profitability of Polish Rural Micro-Enterprises at the Time of EU Accession. Eastern European Countryside, 19, 177-217. doi: https://doi.org/10.2478/eec-2013$\underline{0009}$.

Jenkins, A., Vignoles, A., Wolf, A., \& Galindo-Rueda, F. (2003). The determinants and labour market effects of lifelong learning. Applied Economics, 35(16), 1711-1721.

Koudelková, P., \& Svobodová, P. (2014.) Knowledge creation \& sharing as essential determinants of SMEs innovation. International Economics Letters, 3(1), 12-20. doi: http://dx.doi.org/10.24984/iel.2014.3.1.3.

Lee, M., \& Morris, P. (2016). Lifelong learning, income inequality and social mobility in Singapore. International Journal of Lifelong Education, 35(3), 286-312.

Michailova, J., Mačiulis, A., \& Tvaronavičiené, M. (2017). Overconfidence, risk aversion and individual financial decisions in experimental asset markets. Economic research, Ekonomska istraživanja, 30(1), 1119-1131. doi: http://dx.doi.org/10.1080/1331677X.2017.1311234.

Nguyen, T., Belás, J., Habánik, J., \& Schönfeld, J. (2017). Preconditions of financial safety during lifecycle: the financial literacy and retirement planning in Vietnam. Journal of Security and Sustainability Issues, 6(4), 627-636. doi: https://doi.org/10.9770/jssi.2017.6.4(8). 
Oganisjana, K., Svirina, A., Surikova, S., Grīnberga-Zālīte, G., \& Kozlovskis, K. (2017). Engaging universities in social innovation research for understanding sustainability issues. Entrepreneurship and Sustainability Issues, 5(1), 9-22. doi: https://doi.org/10.9770/jesi.2017.5.1(1).

Power, C., \& Maclean, R. (2011, January). Lifelong learning for poverty alleviation and sustainable development. In International symposium on lifelong learning.

Safrankova, J. M., \& Sikýr, M. (2016). Society, Higher Education and Labour Market. Montenegrin Journal of Economics, 12(3), 167.

Sokól, A., \& Figurska, I. (2017). Creativity as one of the core competencies of studying knowledge workers. Entrepreneurship and Sustainability Issues, 5(1), 23-35. doi: https://doi.org/10.9770/jesi.2017.5.1(2).

Strielkowski, W., \& Ćábelková, I. (2015). Religion, Culture, and Tax Evasion: Evidence from the Czech Republic. Religions, 6(2), 657-669. doi: http://dx.doi.org/10.3390/rel6020657.

Strielkowski, W. (2017). Social and economic implications for the smart grids of the future. Economics \& Sociology, 10(1), 310-318. doi: https://doi.org/10.14254/2071-789X.2017/10-1/22.

UNESCO. (2015). UNESCO Global Network of Learning Cities. Guiding Documents. UNESCO Institute for Lifelong Learning (UIL), Hamburg, Germany. Retrieved from http://uil.unesco.org/ fileadmin/keydocuments/LifelongLearning/learning-cities/en-unesco-global network-of-learning-citiesguiding-documents.pdf.

Voogt, J., Erstad, O., Dede, C., \& Mishra, P. (2013). Challenges to learning and schooling in the digital networked world of the 21st century. Journal of computer assisted learning, 29(5), 403-413.

Zemlickiene, V., Mačiulis, A., \& Tvaronavičiené, M. (2017). Factors impacting the commercial potential of technologies: expert approach, Technological and Economic Development of Economy, 23(2), 410-427 http://dx.doi.org/10.3846/20294913.2016.1271061. 